\title{
Anticorrosion Performance of Epoxy Coating Containing Reactive Poly (o-phenylenediamine) Nanoparticles
}

\author{
Cheng Chen ${ }^{1,2}$, Shihui Qiü, Songlv Qin ${ }^{2}$, Guoping Yan ${ }^{1}$,Haichao Zhao ${ }^{2, *}$, Liping Wang ${ }^{2, *}$ \\ ${ }^{1}$ School of Materials Science and Engineering, Wuhan Institute of Technology, Wuhan, 430074, P. R. \\ China \\ ${ }^{2}$ Key Laboratory of Marine Materials and Related Technologies, Zhejiang Key Laboratory of Marine \\ Materials and Protective Technologies, Ningbo Institute of Materials Technology and Engineering, \\ Chinese Academy of Sciences, Ningbo 315201, P. R. China. \\ *E-mail: zhaohaichao@nimte.ac.cn, wangliping@nimte.ac.cn
}

doi: $10.20964 / 2017.04 .47$

Received: 2 December 2016 / Accepted: 17 February 2017 / Published: 12 March 2017

The free amine-containing poly(o-phenylenediamine) (PoPD) nanoparticles with significant dispersibility in organic solvents have been synthesized by chemical oxidative polymerization of ophenylenediamine mono-hydrochloride salt. The epoxy coatings with different contents of PoPD nanoparticles $(0.5 \mathrm{wt} \%, 1 \mathrm{wt} \%$ and $2 \mathrm{wt} \%)$ were then prepared by curing reaction of epoxy resin, amine hardener and amine containing PoPD nanoparticles. The corrosion protection properties of the as prepared coatings on Q235 steel were investigated by potentiodynamic polarization, open circuit potential (OCP) and electrochemical impedance spectroscopy (EIS) technique in $3.5 \mathrm{wt} \% \mathrm{NaCl}$ aqueous solution for 90 days. The results indicate that the coatings with $0.5 \mathrm{wt} \%$ PoPD nanoparticles (0.5-PDEP) exhibits high anticorrosive performance, which is attributed to the improved barrier effect of the nano-fillers and redox catalytic capability of embedded PoPD nanoparticles with the evidence of scanning electron microscope (SEM) and XRD. This novel amine-containing PoPD nanoparticles give a promising way to enhance the anticorrosion performance of epoxy coatings and potentially have a wider range of applications in anticorrosion related engineering applications.

Keywords: epoxy; poly (o-phenylenediamine) (PoPD); nanoparticle; Q235; anticorrosion coating

\section{FULL TEXT}

(C) 2017 The Authors. Published by ESG (www.electrochemsci.org). This article is an open access article distributed under the terms and conditions of the Creative Commons Attribution license (http://creativecommons.org/licenses/by/4.0/). 